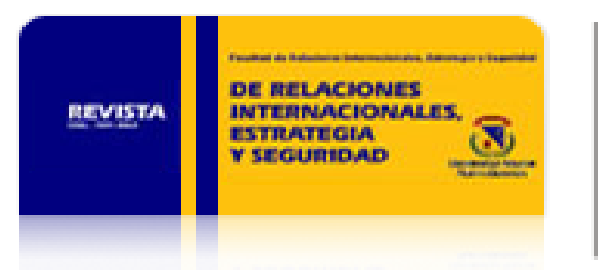

Revista de Relaciones Internacionales, Estrategia y Seguridad

ISSN: 1909-3063

cinuv.relinternal@unimilitar.edu.co

Universidad Militar Nueva Granada

Colombia

Cujabante, Ximena

LA SEGURIDAD INTERNACIONAL: EVOLUCIÓN DE UN CONCEPTO

Revista de Relaciones Internacionales, Estrategia y Seguridad, vol. 4, núm. 2, julio-diciembre, 2009,

pp. 93-106

Universidad Militar Nueva Granada

Bogotá, Colombia

Disponible en: http://www.redalyc.org/articulo.oa?id=92712972007

- Cómo citar el artículo

- Número completo

- Más información del artículo

Página de la revista en redalyc.org

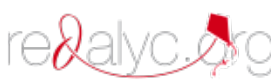

Sistema de Información Científica

Red de Revistas Científicas de América Latina, el Caribe, España y Portugal

Proyecto académico sin fines de lucro, desarrollado bajo la iniciativa de acceso abierto 
rev.relac.int.estrateg.segur.4(2):93-106,2009

\title{
LA SEGURIDAD INTERNACIONAL: EVOLUCIÓN DE UN CONCEPTO
}

\author{
Ximena Cujabante*
}

\section{RESUMEN}

La seguridad hoy en día es un tema de gran importancia tanto en la agenda de política internacional como en la doméstica. En este sentido, la seguridad como concepto ha permeado los diferentes estamentos de la sociedad. Desde su reconceptualización, después del fin de la Guerra Fría, la seguridad como concepto ha pasado a incluir diferentes sujetos objetos de amenazas así como una gran variedad de éstas. Las diferentes teorías de relaciones internacionales han estado presentes para explicar no sólo la dinámica propia del sistema internacional, sino que también ha fundamentado la evolución de un concepto tradicional de seguridad sustentado en el realismo político, a un nuevo concepto basado en la interdependencia compleja.

\footnotetext{
* Magíster en Relaciones Internacionales de la Universidad Externado de Colombia. Especialista en Negociación y Asuntos Internacionales de la Universidad de los Andes. Politóloga de la Universidad Javeriana. Directora del Programa de Relaciones Internacionales y Estudios Políticos e la Universidad Militar Nueva Granada. xcujabante17@yahoo.com.mx.
} 
Palabras clave: Seguridad tradicional, Reconceptualización de la seguridad, seguridad y Guerra Fría, Seguridad Post Guerra Fría, Seguridad y Realismo político, seguridad e interdependencia.

\begin{abstract}
Security nowadays is a theme of great importance, both in the international politics and in the domestic agendas. In this sense, security as a concept has permeated the different spheres of society. Since its re-characterization after the end of the Cold War, security as a concept has gone to include a diversity of subjects, objects of threats, as well as a great variety of these. The different theories of international relations have been present to explain not only the own dynamics of the international system, but have also supported the evolution of a traditional concept of security supported in the political realism, to a new concept based on complex interdependency.
\end{abstract}

Key words: Traditional security, Re-characterization of security, security and Cold War, Security Post Cold War, Security and political Realism, security and interdependency

La seguridad internacional, hoy por hoy, es un tema de gran interés, no sólo para académicos, sino para los diferentes líderes de gobierno que han presenciado las diversas transiciones que ha sufrido el sistema internacional y, subsecuentemente, el concepto de seguridad en sus diversos ámbitos.

Sin embargo, los debates sobre la naturaleza y el significado de la "seguridad», así como el futuro de los estudios sobre la misma, se ubican en el período de Post Guerra Fría ${ }^{1}$. Dichos debates tienen sus orígenes en: el descontento existente entre algunos académicos frente a los planteamientos realistas y neorrealistas que han caracterizado el tema, una necesidad de responder a los desafíos propios de la seguridad en el periodo de la post Guerra Fría y un continuo deseo de lograr que la disciplina sea relevante en los asuntos contemporáneos.

A pesar de ello, después de mucha discusión, los académicos no han logrado un consenso en la aproximación a la construcción de un concepto de seguridad, pues para algunos autores la seguridad debe ser analizada desde el concepto tradicional, mientras que para otros, éste se queda corto en la explicación de la realidad mundial. Así que, sugieren una ampliación del tema tanto en la dimensión sujeto como en la agenda.

El presente artículo busca hacer una revisión de la evolución que ha tenido el concepto de seguridad internacional durante los siglos XX y XXI a partir de las teorías de las relaciones internacionales

\footnotetext{
${ }^{1}$ KRAUSE Keith y WILLIAMS Michael. Broadening the Agenda of Security Studies: Politics and Methods. En: Mershon International Studies Review, No. 40, 1996, p. 229.

LA SEGURIDAD INTERNACONAL: EVOLUGIÓN DE UN CONCEPTO
} 
La principal evidencia de la falta de consenso en el estudio de la seguridad, como concepto de relaciones internacionales, se puede encontrar en la literatura ${ }^{2}$. En este sentido, al revisar el material bibliográfico sobre el tema, se encuentra que los diferentes autores aún no han podido definir con claridad algunos interrogantes como ¿Qué se entiende por seguridad? ¿Hacia quién debe ir direccionada la seguridad?, ¿Cuál es o cuáles son las amenazas a la seguridad? y ¿Qué métodos utilizar para contrarrestar las amenazas no tradicionales? Al consultar diferentes escritos, se encuentran diversas posiciones que de una u otra forma tratan de dar respuesta a los cuestionamientos anteriormente mencionados. Así, las teorías clásicas de relaciones internacionales, como el realismo, el neorrealismo, la interdependencia y algunas post-positivistas, como la teoría crítica y el constructivismo, se han convertido en herramientas útiles para el debate en la conceptualización de la seguridad internacional.

Hasta hace relativamente poco, la falta de exploración académica en el tema de la seguridad estaba íntimamente relacionada con el hecho de que el estudio académico se limitaba a los temas estratégicos que eran de interés para el estamento militar, dificultando así el acercamiento de estudiosos de otras disciplinas.

Es pertinente anotar que los diferentes estudios recientes sobre el tema han tratado de abordar la seguridad internacional a partir de una "clasificación» temporal, es decir, durante la Guerra Fría y post-Guerra Fría, marcando una diferencia en el concepto de la misma. Esto, debido a que el entorno internacional en cada uno de estos períodos presentó características disímiles, lo cual contribuyó a que el concepto de seguridad fuera entendido de formas diferentes. Así, el concepto de seguridad imperante durante la Guerra Fría fue revaluado durante el período post Guerra Fría, introduciéndose nuevos sujetos de seguridad y, asimismo, ampliándose la agenda de amenazas a la misma. Por otro lado, se encuentran aquellos análisis que profundizan en la concepción que tienen los países del Tercer Mundo o países subdesarrollados sobre la seguridad y sus implicaciones, así como aquellos escritos que se centran en la visión que tienen los países industrializados o desarrollados sobre la seguridad internacional y su papel para el mantenimiento de la misma.

En este sentido, a lo largo de este capítulo, se intentarán abordar algunas de las diversas posturas que existen en lo que a seguridad se refiere, partiendo del concepto tradicional, para luego abordar los nuevos conceptos y así entrar a analizar los debates sobre seguridad.

\section{CONCEPTO TRADICIONAL DE SEGURIDAD}

El concepto tradicional de seguridad debe mucho a los aportes de los autores de la escuela realista que, como Hans Morgenthau, brindaron a través de sus escritos una forma de analizar y entender el mundo a partir de la concepción del poder. Es pertinente anotar que esta forma de ver el mundo

\footnotetext{
${ }^{2}$ BUZAN Barry. People, States and Fear. Colorado: Lynne Rienner Publishers, second edition , 1991, p. 3.
} 
tomó gran relevancia en el período posterior a la Segunda Guerra Mundial, cuando Estados Unidos, en su afán por establecer su papel en el sistema internacional, brindó apoyo a académicos de diferentes partes del mundo para que a través de sus análisis y su quehacer político delimitaran la política exterior de este Estado en su nueva posición mundial. Cabe anotar que para ese entonces ya se hablaba de un paradigma idealista que sustentaba la paz mundial en la fundación de organizaciones internacionales que garantizaran una seguridad colectiva. Sin embargo, esta visión idealista de la paz en el sistema internacional fue fuertemente criticada por el realismo, basando sus argumentos en el fracaso de la Liga de Naciones para evitar la Segunda Guerra Mundial ${ }^{3}$.

El realismo se constituía así en un paradigma de las relaciones internacionales, caracterizado por tratar de entender y explicar los principales problemas que surgían en las relaciones internacionales: la guerra y la paz. Asimismo, ofrecía una explicación de los hechos internacionales y se convertiría en una guía para la construcción de otras teorías y la investigación en el campo de las relaciones internacionales.

Para entender mejor la relación que existe entre el realismo y el tema de seguridad, se revisarán algunos de los planteamientos propuestos por Hans Morgenthau, que permitirán entender por qué el concepto tradicional de seguridad debe mucho a la concepción realista del sistema internacional.

Los realistas parten por reconocer que el sistema internacional es anárquico, es decir, que hay una ausencia de gobierno central, en donde cada uno de los Estados que componen el sistema internacional ejerce su soberanía sobre su territorio y asuntos, siendo los Estados los únicos actores pertinentes del sistema internacional. En este contexto, aparece la autoayuda como la principal motivación que tienen los Estados en el sistema internacional, entendiéndose por autoayuda la necesidad de cada Estado de velar por sus propios intereses, lo cual conlleva al conflicto entre Estados.

Poco a poco la dinámica del sistema internacional es explicada por los realistas, quienes dan la entrada triunfal al poder como tema central de la política internacional. Para Morgenthau, la importancia que reviste el poder "es universal en tiempo y espacio» ${ }^{4}$ y se "convierte en el objetivo inmediato de cualquier nación $»^{5}$. En consecuencia, los realistas plantean que los actores del sistema internacional (los Estados) estarán en una lucha constante por el poder, el cual es definido por Hans Morgenthau, en su libro «Política entre las Naciones. La lucha por el poder y la paz», como "el control del hombre sobre las mentes y las acciones de otros hombres» ${ }^{6}$. Y por poder político

\footnotetext{
${ }^{3}$ HOFFMAN Stanley. Jano y Minerva: Ensayos sobre la guerra y la paz. Argentina: Grupo Editor Latinoamericano, 1987, p. 79-88.

${ }^{4}$ MORGENTHAU Hans. Política entre las Naciones. La lucha por el poder y la paz. Buenos Aires: Editorial Sudamericana, 1960, p. 48.

${ }^{5}$ Ibid., p. 41.

${ }^{6}$ Ibid., p. 43.

LA SEGURIDAD INTERNACIONAL: EVOLUGIÓN DE UN CONCEPTO
} 
entiende «una relación psicológica entre quienes ejercen y aquellos sobre los que se ejerce. Dicha relación otorga a los primeros control sobre ciertas acciones de los segundos mediante el impacto que ejercen sobre las mentes de los últimos. Dicho impacto deriva de: la expectativa de beneficios, el temor a las desventajas y el respeto o amor hacia los hombres o las instituciones. Puede ejercerse mediante órdenes, amenazas, la autoridad o carisma de un hombre o a través de la combinación de cualquiera de estos factores» ${ }^{7}$.

Morgenthau plantea que el poder político debe distinguirse de la fuerza en el ejercicio de la violencia física. Cuando la violencia se convierte en realidad, el poder político cede a favor del poder militar o seudo militar. Especialmente en política internacional, la fuerza armada, como amenaza, es el factor material más importante que contribuye a conformar el poder político de una nación. Así, la fuerza se puede utilizar como instrumento de política exterior, aceptando daños limitados y riesgos mensurables para quien la emplea, convirtiéndose su uso en un instrumento que permite quebrar la voluntad de la otra parte, y de esta forma se estará ejerciendo poder ${ }^{8}$.

Aun cuando en la dinámica del sistema internacional el poder se constituye en una aspiración que persiguen los Estados, las ideologías permiten involucrarse en la lucha por el poder en forma psicológica y moralmente aceptable para los actores y para el auditorio. Estos principios legales y éticos, y las necesidades biológicas, cumplen una función doble en la esfera de la política internacional. Son los fines últimos de la acción política, o son los pretextos y falsos frentes tras los cuales el elemento de poder, inherente a toda política, se oculta. Estos principios y necesidades pueden cumplir una función u otra, o pueden cumplir ambas al mismo tiempo. Para ejemplificar lo anteriormente enunciado, Morgenthau plantea que «un principio legal y ético, como la justicia, por ejemplo, o una necesidad biológica, como un adecuado nivel de vida, puede ser la meta de una política exterior, o puede ser una ideología, o puede ser ambas cosas al mismo tiempo»⿳9.

En este sentido, un Estado puede apoyarse en principios éticos para instrumentar políticas exteriores tendientes a conservar el poder y evitar el cambio de la distribución de poder en su favor, desarrollando una política de statu quo; o puede orientarla hacia la adquisición de un mayor poder mediante el cambio de la estructura de poder existente a través de una política imperialista; o puede intentar mostrar el poder que posee para mantenerlo o incrementarlo, desarrollando una política de prestigio.

La descripción que hacen los realistas del elemento poder y su lucha por conseguirlo en el sistema internacional, permite vislumbrar que si los diferentes Estados del entorno mundial tienen como objetivo inmediato su consecución, el conflicto entre los mismos será un escenario permanente en

\footnotetext{
7 Ibid., p. 43.

${ }^{8}$ Ibid., p. 44.

9 Ibid., p. 123.
} 
el entorno mundial. En este orden de ideas, los recursos militares cobran gran importancia y tienen gran trascendencia bajo la concepción realista.

Al analizar los factores que fundamentan el poder nacional, se puede entrever que cada uno por separado y en conjunto propende por un fortalecimiento del poderío nacional, direccionado hacia el tema militar. Dichos elementos permiten vislumbrar la magnitud que reviste la capacidad militar en la lucha por el poder que libran los Estados y en la implementación de políticas, ya sean de statu quo, imperialistas o de prestigio. Asimismo, reviste de gran importancia para un Estado poder contar con aquellos factores que hacen parte del poder nacional, para de una u otra forma poder asegurar la victoria en la guerra, y en tiempos de paz focalizar toda la atención en la política internacional.

Como consecuencia, la seguridad de los Estados dependerá del uso de la fuerza. En este sentido, la guerra y la constante posibilidad de guerras hacen que la anarquía del sistema internacional se convierta en lo que Hobbes denomina «una guerra de todos contra todos»"

El panorama planteado por Hans Morgenthau acerca del sistema internacional permite entender que la seguridad de un Estado, vista desde la concepción realista, está íntimamente relacionada con la capacidad militar que tenga un Estado determinado. En este sentido se podría plantear que, desde el realismo, un Estado estará seguro siempre y cuando tenga la suficiente capacidad militar como para poder responder a políticas de statu quo, imperialistas o de prestigio, llevadas a cabo por actores del sistema internacional, además de contar con los recursos necesarios para ir a la guerra si fuera necesario. Debido a que cualquier Estado podría recurrir al uso de la fuerza, todos los Estados deben estar preparados para hacer lo mismo.

En este sentido, si cada uno de los Estados del escenario mundial está buscando afianzar su poder nacional a través del fortalecimiento de los factores que lo conforman, intentando buscar su seguridad, cada uno de los actores del sistema internacional se convierte en una amenaza para la seguridad del otro. Más si se tiene en cuenta que la arena internacional se caracteriza por la autoayuda, en donde los Estados, en últimas, solamente pueden confiar en sus propios esfuerzos por mantener su seguridad. Esto lleva a concluir que si las amenazas a la seguridad de un Estado provienen de otras naciones, las amenazas a la seguridad del Estado, desde la visión realista, son externas al mismo.

La existencia de la autoayuda, concepto neorrealista propuesto por Kenneth Waltz ${ }^{11}$, y la lucha por el poder en el sistema internacional conllevan al dilema de seguridad, el cual consiste en que si un Estado realiza una acción determinada, el otro Estado o Estados deberán tomar medidas para responder a dicha acción. Entre mayores capacidades tenga un Estado para garantizar su seguridad, mayor será la amenaza que representa para los demás Estados, promoviéndose así, que estos últi-

${ }^{10}$ CROFT Stuart, JAMES Lucy, MORGAN Patrick. Security Studies Today. Great Britain: Polity Press, p. $31-32$.

${ }^{11}$ WALTZ Kenneth. Teoría de la Política Internacional. Buenos Aires: Grupo Editor Latinoamericano, 1988, p. 174.

LA SEGURIDAD INTERNACIONAL: EVOLUCIÓN DE UN CONCEPTO 
mos intenten adquirir capacidades similares que garanticen su seguridad y puedan responder a determinada acción. En otras palabras, el grado de amenazas a un Estado está determinado por las acciones de otros Estados y depende de su habilidad de imponerse o resistir a los esfuerzos de otros Estados por sobreponerse a éste. La capacidad descansa en el poder o en la posibilidad de estar de igual a igual frente a otros. En consecuencia, el dilema de seguridad genera y refuerza la inseguridad en los Estados y por consiguiente en el escenario internacional ${ }^{12}$.

Partiendo de que los Estados son inherentemente peligrosos y conflictivos, debido a su comportamiento promovido por la esencia del sistema internacional o por la misma naturaleza de los Estados e individuos, autores como Croft plantean que las relaciones internacionales se caracterizan por $^{13}$ :

1. La espontaneidad o insuficiencia de contener la competencia entre los Estados por el poder (y otros intereses que se obtienen vía poder), elemento principal de la inseguridad ${ }^{14}$.

2. La persecución de la seguridad en la base de la autoayuda ${ }^{15}$.

3. La necesidad de confiar en el uso de la fuerza y la presencia de amenazas en numerosas instancias (competencia por el poder y la necesidad de actuar en la base de la autoayuda) que promueven la inseguridad ${ }^{16}$.

De esta forma, la visión realista reduce las relaciones internacionales a lo más esencial, el manejo de la seguridad y la competencia por los elementos de poder. En este sentido, al analizar el comportamiento de los miembros de cualquier sistema internacional se debe tener en cuenta la distribución del poder y la jerarquía que se establece a partir de la lucha por el poder para garantizar su seguridad.

En la década del setenta surge la teoría de la interdependencia como una herramienta útil a la hora de explicar el escenario mundial, así como el tema de la seguridad. Como lo plantearan Keohane y Nye, la interdependencia compleja se caracteriza por considerar en sus análisis una multiplicidad de actores, es decir, que el Estado ya no es el único actor de la escena global, sino que también entran a hacer parte actores no gubernamentales. En este sentido, la interdependencia busca redefinir la centralidad otorgada por el realismo al Estado-Nación como unidad de investigación, desagregando sus componentes para lograr una mejor y más completa descripción del sistema internacional ${ }^{17}$. En cuanto a la agenda de relaciones interestatales, ésta va a estar conformada por múltiples temas que no están bajo una jerarquía clara o sólida, lo cual significa, entre otras cosas, que la seguridad militar no domina consistentemente la

\footnotetext{
${ }^{12}$ MORGENTHAU Hans, Op. cit., p, 13-763.

${ }^{13}$ CROFT Stuart, JAMES Lucy, MORGAN Patrick, Op. cit., p. 53.

${ }^{14}$ Ibid., p. 53.

15 Ibid., p. 54.

16 Ibid., p. 54.

17 TOKATLIAN Juan Gabriel y PARDO Rodrigo. Política Exterior Colombiana: ¿De la subordinación a la autonomía? Bogotá: Ediciones Uniandes-Tercer Mundo Editores, 1989, p. 24.
} 
agenda. Muchos temas surgen de la denominada política interna, volviéndose internacionales y haciéndose así cada vez más difusa la diferenciación entre temas internos y externos ${ }^{18}$.

De esta forma, en un mundo interdependiente, en donde existen múltiples problemas, en el cual las coaliciones son transnacionales y transgubernamentales, el papel potencial de las instituciones internacionales para la negociación política crece considerablemente, pues éstas contribuyen a establecer la agenda internacional y además actúan como catalizadores para la formación de coaliciones y como escenario para iniciativas políticas y para la vinculación de aquellos Estados débiles ${ }^{19}$. En este contexto, aparece el concepto de cooperación como una pieza fundamental, debido a que se le otorga una connotación amplia que no sólo incluye las relaciones Norte-Norte, sino también las Norte-Sur y Este-Oeste ${ }^{20}$.

Keohane, plantea que se debe distinguir entre cooperación y armonía. Esta última se refiere a una situación en la que las políticas de los actores automáticamente facilitan el logro de los propósitos de otros ${ }^{21}$, mientras que la cooperación requiere que las acciones de individuos u organizaciones, que no se hallan en armonía preexistente, se adecúen mutuamente por medio de un proceso de negociación, al que generalmente se designa "coordinación de políticas». En este sentido, la cooperación se produce cuando los actores adaptan sus conductas a las preferencias presentes o anticipadas de otros, siendo ésta altamente política, pues de algún modo deben alterarse los esquemas de conducta $^{22}$. De ahí que se plantee que el concepto de régimen internacional, entendido como «el conjunto de principios, normas, reglas y procedimientos decisionales en torno a los cuales convergen las expectativas de los actores en una determinada área de las relaciones internacionales ${ }^{23}$, permite describir las estructuras de cooperación. Asimismo, la cooperación se debe analizar dentro del contexto de las instituciones internacionales, pues cada acto de cooperación afecta las convicciones, normas y prácticas que forman el escenario de acciones futuras ${ }^{24}$.

Como se puede apreciar, la teoría de la interdependencia en su análisis del sistema internacional da cabida a nuevos elementos que no son contemplados por el realismo, y que hacen que el estudio de la realidad internacional sea más inclusivo, profundo y, sobre todo, que brinda herramientas que permiten entender el escenario internacional de la post Guerra Fría, enriqueciendo el debate que en la actualidad se desarrolla en el tema de la seguridad internacional.

\footnotetext{
${ }^{18}$ KEOHANE Robert y NYE Joseph. Poder e Interdependencia. Buenos Aires: GEL, 1988, p. 41

19 Ibid., 54.

20 TOKATLIAN Juan Gabriel y PARDO Rodrigo, Op. cit., p. 34-35.

${ }^{21}$ KEOHANE Robert. Cooperación y Regímenes Internacionales. En: KEOHANE Robert. Después de la Hegemonía. Cooperación y Discordia en la Política Económica Mundial. Buenos Aires: GEL-RIAL, 1988, p. 73-74.

22 Ibid., p. 75.

${ }^{23}$ Ibid., p. 81.

24 Ibid., p. 79-80.

LA SEGURIDAD INTERNACIONAL: EVOLUGÓN DE UN CONCEPTO
} 
De hecho, las Ilamadas amenazas no tradicionales a la seguridad, propias de la post Guerra Fría, se pueden analizar desde la óptica de la interdependencia, en la medida en que éstas se caracterizan porque la mayoría de ellas no se centran en el Estado como sujeto de seguridad, sino que emanan en su mayoría de actores de carácter sub-estatal o trans-estatal. De acuerdo con esto, no se identifican fácilmente con los análisis y teorías centradas en el Estado, como la teoría realista; además, estas amenazas no tienen un lugar geográfico con el cual se puedan identificar. En la visión realista, el foco de peligro se ubica en el poder militar que otros Estados poseen y en la utilización de estos recursos para contener la amenaza. En el mundo del realismo, el sine qua non de la seguridad es la construcción y el mantenimiento de los balances militares en las regiones estratégicas. Las amenazas no tradicionales, por su parte, representan un peligro difuso, en la medida en que la fuente de donde provienen es indeterminada, multidimensional, en la medida en que las amenazas pueden provenir de diferentes temas y multidireccional, pues estas amenazas pueden atentar contra la seguridad de actores tanto estatales como no estatales. Además, estas amenazas no pueden ser manejadas solamente por las políticas de defensa tradicionales, es decir, a través de la utilización de los recursos militares, sino que se deben buscar nuevas formas de contrarrestarlas, pues en la mayoría de los casos la utilización de la fuerza no ha sido la herramienta más útil, si tiene en cuenta que estas «nuevas» amenazas presentan características disímiles a las tradicionales. Finalmente, los análisis que se han elaborado sobre este tema sugieren que se deben ampliar los sujetos objeto de seguridad y dejar de considerar al Estado como el único actor cuando de seguridad se trate ${ }^{25}$.

La teoría realista de las relaciones internacionales, en su explicación de la dinámica del sistema internacional, pareciera abordar de manera completa el tema de la seguridad de los Estados en el entorno mundial. Sin embargo, ha surgido un debate en el período posterior a la Guerra Fría en torno a la concepción tradicional de la seguridad, pues para algunos analistas, la exploración de la seguridad en el sistema internacional se queda corta a la luz de esta teoría, en la medida en que ésta solo contempla a los Estados como únicos actores y en el mundo interdependiente de hoy también se incluyen actores no estatales que podrían jugar un papel preponderante en lo que a seguridad se refiere.

\section{LA SEGURIDAD COMO CONCEPTO EN EL PERIODO POST GUERRA FRÍA}

Como se abordó en la primera parte de este capítulo, la seguridad en términos tradicionales estudia la seguridad estatal/nacional, siendo el Estado el único actor objeto de seguridad, y en donde los temas militares se convierten en prioritarios dentro de la agenda de política internacional. De acuerdo con esto, desde la concepción tradicional (realista), las amenazas a la seguridad van a estar dadas por el uso de la fuerza por parte de los Estados.

${ }^{25}$ Ibid., p. 116. 
Aun cuando para algunos autores, como Rockwell y Moss, esta visión representa una «teoría coherente, aunque limitada de la seguridad nacional ${ }^{26}$, en el periodo de posguerra fría han sido frecuentes las exhortaciones a favor de una reconceptualización de la seguridad. El convulsionado escenario después de la Guerra Fría ha alterado drásticamente el contexto de la seguridad global, en la medida en que en la actualidad se habla de un mundo interdependiente en donde tienen cabida una multiplicidad de actores y una diversidad de temas en la agenda de política internacional. Así, el Estado ya no es el único actor del sistema internacional y además aparecen una variedad de asuntos que vienen a complementar el aspecto militar. Bajo estas circunstancias, el concepto tradicional de seguridad se ha visto impactado, invitando no sólo a repensarlo sino a reconceptualizarlo ${ }^{27}$.

De acuerdo con esto, ha surgido un debate en torno a la concepción de seguridad, planteada por los realistas, en la medida en que para muchos analistas ésta es limitada y no contempla elementos de la agenda de seguridad de los Estados que podrían ser objeto de análisis. En este sentido, se ha generado un debate académico en torno a la reconceptualización del concepto de seguridad, el cual ha girado en torno a dos ejes: por un lado, aquellos denominados "expansionistas», y por otro lado, la división más importante que se da entre los enfoques críticos y los enfoques constructivistas ${ }^{28}$.

En cuanto a los expansionistas, éstos plantean que desde finales de la década de los ochenta, con la apertura de la Unión Soviética, que marcó el fin de la Guerra Fría, se debilitó el concepto del «enemigo externo", y se volvió a presentar la idea en los círculos académicos de que era necesario equilibrar el concepto de seguridad nacional, incluyendo otros aspectos de naturaleza no estratégica, así como una serie de nuevas amenazas que eran consideradas "como el principal enemigo de la estabilidad política y democrática", tales como el narcotráfico, el terrorismo, la degradación del medio ambiente, la deuda y la pobreza, entre otros. De ahí que un buen número de investigadores hayan convenido en la necesidad de ampliar el concepto de seguridad nacional para ajustarlo al nuevo orden mundial, lo cual ha derivado en una reconsideración de los conceptos tradicionales de seguridad internacional, hemisférica, regional y subregional en diferentes contextos geográficos ${ }^{29}$.

Otro de los argumentos que se presentan a favor de una ampliación del concepto y de las agendas de seguridad nacional de los diferentes países del continente americano, se refiere a que las amenazas «reales» que enfrentan actualmente los Estados tienen su origen en el atraso económico, lo cual lleva a pensar que la amenaza no se origina en un enemigo externo, sino que es el resultado de factores internos generados por las disparidades en los niveles de desarrollo, lo cual demuestra la necesidad de incorporar los aspectos de carácter económico y social ${ }^{30}$.

${ }^{26}$ ROCKWELL Richard y MOSS Richard. La reconceptualización de la seguridad: un comentario sobre la investigación. En:_AGUAYO Sergio y BAGLEY Bruce (Comps.). En busca de la seguridad perdida. México D.F.: Siglo XXI, 1990, p. 44.

${ }^{27}$ CROFT Stuart, JAMES Lucy, MORGAN Patrick, Op. Cit., p. 115.

${ }^{28}$ HURRELL Andrew. Seguridad y violencia en América Latina. En: Revista Foro Internacional, enero-marzo 1998, volumen 38, Colegio de México, p. 20-21.

${ }^{29}$ DE LA LAMA Jorge. El nuevo concepto de Seguridad Hemisférica Cooperativa. Chile: FLACSO, 1998, p. 12.

${ }^{30}$ Ibid., p. 14.

LA SEGURIDAD INTERNACIONAL: EVOLUCOÓN DE UN CONCEPTO 
Los expansionistas plantean tres argumentos centrales: 1) que el Estado ya no es el único objeto de referencia de la seguridad, sino que se debe incluir a los individuos y colectividades, a la humanidad en su conjunto, la gente en general, la biosfera, entre otros; 2) que cualquier análisis significativo de la seguridad debe considerar la importancia de un rango de amenazas mucho más amplio, entre las que se incluyen aquellas cuyo origen se encuentra en la destrucción ambiental, en la vulnerabilidad económica y en la descomposición de la cohesión social y; 3) que la responsabilidad de proveer seguridad radica no sólo en el Estado, sino en instituciones internacionales y en organizaciones no gubernamentales ${ }^{31}$.

En este mismo sentido, Barry Buzan plantea la necesidad de ampliar el concepto de seguridad hacia uno que trascienda las limitadas nociones de defensa militar y esté más acorde con el mundo interdependiente de hoy ${ }^{32}$. Buzan sugiere que la seguridad de las colectividades humanas es afectada en cinco sentidos: militar, político, económico, social y del medio ambiente.

Los estudios críticos en seguridad, por su parte, plantean un rechazo del concepto tradicional de seguridad. Rechazan particularmente las políticas que ponen al Estado y su soberanía en el centro del tema, la autoridad moral de los Estados, la creencia de que el Estado es y puede ser el guardián de la seguridad de las personas. De ahí que, propongan la ampliación de la agenda de seguridad, en la cual el tema militar es sólo un aspecto de la misma y en donde el Estado es un actor más dentro de otros referentes ${ }^{33}$.

En cuanto al debate que ha surgido entre los enfoques objetivistas y los enfoques constructivistas, es pertinente anotar que la mayoría de los análisis tradicionalistas de la seguridad adoptan un enfoque decididamente objetivista y materialista. Sus orígenes se encuentran en el carácter anárquico de las relaciones internacionales y en el grado en que la capacidad material de los adversarios crea amenazas objetivas para la seguridad nacional. Asimismo, los expansionistas adoptan un enfoque fundamentalmente similar. Sigue considerándose que la seguridad está relacionada con factores materiales y objetivos, aunque su rango y alcance son ahora mucho más amplios e inclusivos. Los constructivistas, por su parte, plantean que las fuerzas y los factores materiales importan, pero sólo dentro de un contexto histórico de prácticas específicas que crean intereses e identidades y dan pie a entendimientos ${ }^{34}$.

Como lo planteara Hurrell, la seguridad y la securitización son procesos intersubjetivos que se construyen socialmente y que cambian a lo largo del tiempo. Así, la seguridad se refiere a la interacción entre fuerzas materiales y entendimientos intersubjetivos. En este sentido, este autor

\footnotetext{
${ }^{31}$ HURRELL Andrew, Op.cit., p. 21.

${ }^{32}$ BUZAN Barry, Op.cit., p. 6.

${ }^{33}$ BOOTH Ken. Security and Self. En:KRAUSE Keith y WILLIAMS Michael. Critical Security Studies. Estados Unidos: University of Minnesota Press, p. 106-107.

${ }^{34}$ HURRELL Andrew, Op.cit., p. 21.
} 
plantea que se debe tener mucho cuidado en aclarar la manera precisa como un problema llega a ser considerado un asunto de seguridad, es decir securitizado. Frente a este tema, Ole Weaver plantea que un asunto se convierte en un problema de seguridad nacional porque un grupo o institución particular logra incluirlo de manera forzada en la agenda correspondiente, no porque sea importante o constituya una amenaza objetiva ${ }^{35}$. Waever plantea que la securitización exitosa sirve para poner un tema fuera de los dominios de la política normal y para justificar determinados tipos de respuesta política, especialmente respuestas coercitivas ${ }^{36}$.

En este sentido, la seguridad se convierte en una práctica, una forma específica de enmarcar un problema. De ahí que, con la ayuda del lenguaje teórico, se pueda denominar a la seguridad como un discurso que se caracteriza por dramatizar un problema como si éste tuviera prioridad absoluta, lo que significa que el Estado debe desarrollar todas las acciones necesarias en una determinada área, justificando las medidas para contrarrestar la amenaza ${ }^{37}$.

Aun cuando se ha generado una discusión en torno a la reconceptualización de la seguridad, no se ha logrado un consenso entre los académicos, debido a que no se ha podido definir de manera clara cuáles serían los actores y los sujetos objeto de seguridad y además cuáles serían las medidas adecuadas para contrarrestar algunas de las amenazas que aparecen en la agenda de seguridad de los Estados. Además, surge otro inconveniente, y es que si se amplía el concepto de seguridad, cualquier tema podría llegar a convertirse en una amenaza para la seguridad de un Estado, lo cual conllevaría a la securitización en las agendas de seguridad estatales. Es decir, que se plantearía el interrogante de hasta dónde la seguridad puede verse objetivamente en un discurso político, utilizado en función de los intereses de grupos específicos.

Al analizar estos puntos de discordia, se puede encontrar que todos están relacionados unos con otros. Si no se tiene un sujeto o sujetos claros, difícilmente se podrán encontrar las amenazas que atentan contra su seguridad y, por consiguiente, la forma de manejarlas. Esta diversidad de amenazas potenciales incluye la degradación del medio ambiente, el crecimiento de la población, el agotamiento de los recursos naturales, la mala administración y el deterioro económicos; el creciente poder de corporaciones multinacionales, la sustitución de los valores tradicionales de una cultura por influencias culturales «extranjeras», el aumento de la estratificación social y económica, la crisis de los sistemas de salud pública, el autoritarismo y la represión, la violación de los derechos humanos e incluso desastres naturales como terremotos ${ }^{38}$.

\footnotetext{
${ }^{35}$ WAEVER Ole. Securitization and Desecuritization. En: LIPSCHUTZ Ronnie. On Security. New Cork: Columbia University Press, 1995, p. 54.

${ }^{36}$ Ibid., p. 56.

37 Ibid., p. 55.

${ }^{38}$ Ibid., p. 55.

LA SEGURIDAD INTERNACIONAL: EVOLUGÓN DE UN CONCEPTO
} 
La aparición de estas «nuevas» amenazas, a partir del movimiento generado en los años ochenta, hacia una ampliación en la agenda de seguridad desde un enfoque estrictamente centrado en el Estado, hacia una seguridad incluyente de la colectividad internacional, donde nuevas y variadas amenazas tienen cabida, ha traído como consecuencia que la seguridad sea concebida como todo aquello políticamente deseable o atractivo. Entonces surge un problema para los estudios de seguridad, que consiste en determinar hasta qué punto un determinado tema puede ser objeto de amenaza a la seguridad. Es decir, que debido a la ampliación de la agenda de seguridad, se están securitizando las agendas de política internacional por parte de los Estados, pues cualquier tema puede ser justificado por los Estados como amenaza a su seguridad y así formular e implantar políticas sustentadas en la búsqueda de la seguridad, cuando dicho tema puede ser manejado de otra forma. De ahí que Waever plantee que la securitización es una herramienta con la que cuentan los Estados, pero que se debe saber utilizar, y que así como se puede securitizar la agenda, también se debe tener la capacidad de desecuritizar (desligar determinados asuntos de la agenda de seguridad) algunos temas que pueden ser tratados vía otra tematización ${ }^{39}$.

\section{CONCLUSIÓN}

Aun cuando a lo largo de este artículo se ha abordado la seguridad desde un marco teórico, apoyado en algunas de las teorías de relaciones internacionales, se dificulta la elaboración de una definición cerrada de la seguridad, pues actualmente el concepto es tan amplio y abarca tan diversos y variados temas como actores, que lo que es seguridad para unos puede ser amenaza a la seguridad de otros. Además, debe sumársele otro ingrediente, y es el fenómeno de la securitización de las agendas, lo cual ha permitido que cualquier tema pueda convertirse a través del discurso político en un tema más de la agenda de seguridad de un Estado, y además de forma justificada. De ahí que, mientras no se llegue a un consenso entre jefes de Estado, líderes políticos, académicos, entre otros, sobre lo que se va entender por seguridad, el término y, por lo tanto, su concepción van a seguir siendo abordados y trabajados de manera subjetiva.

\section{BIBLIOGRAFÍA}

BOOTH Ken. Security and Self. En:KRAUSE Keith y WILLIAMS Michael. Critical Security Studies. Estados Unidos: University of Minnesota Press, p. 100-107.

BUZAN Barry. People, States and Fear. Colorado: Lynne Rienner Publishers, second edition , 1991, p.3-207.

CROFT Stuart, JAMES Lucy, MORGAN Patrick. Security Studies Today. Great Britain: Polity Press, p. 31- 32, 53-57, 115.

${ }^{39}$ WAEVER Ole, Op.cit., p. 47-84. 
DE LA LAMA Jorge. El nuevo concepto de Seguridad Hemisférica Cooperativa. Chile: FLACSO, 1998, p. 12- 53

HOFFMAN Stanley. Jano y Minerva: Ensayos sobre la guerra y la paz. Argentina: Grupo Editor Latinoamericano, 1987, p. 79-88.

HURRELL Andrew. Seguridad y violencia en América Latina. En: Revista Foro Internacional, enero-marzo 1998, volumen 38, Colegio de México, p. 20-21.

KEOHANE Robert y NYE Joseph. Poder e Interdependencia. Buenos Aires: GEL, 1988, p. 41-54.

Cooperación y Regímenes Internacionales. En: KEOHANE Robert. Después de la Hegemonía. Cooperación y Discordia en la Política Económica Mundial. Buenos Aires: GEL-RIAL, 1988, p. 73-74, 75, 79, 80- 85, 116.

KRAUSE Keith y WILLIAMS Michael. Broadening the Agenda of Security Studies: Politics and Methods. En: Mershon International Studies Review, No. 40, 1996, p. 229.

MORGENTHAU Hans. Política entre las Naciones. La lucha por el poder y la paz. Buenos Aires: Editorial Sudamericana, 1960, p. 763.

ROCKWELL Richard y MOSS Richard. La reconceptualización de la seguridad: un comentario sobre la investigación. En: AGUAYO Sergio y BAGLEY Bruce (Comps.). En busca de la seguridad perdida. México D.F.: Siglo XXI, 1990, p. 44.

TOKATLIAN Juan Gabriel y PARDO Rodrigo. Política Exterior Colombiana: ¿De la subordinación a la autonomía? Bogotá: Ediciones Uniandes-Tercer Mundo Editores, 1989, p. 24, 34, 35.

WAEVER Ole. Securitization and Desecuritization. En: LIPSCHUTZ Ronnie. On Security. New Cork: Columbia University Press, 1995, p. 54, 55, 56, 47-84.

WALTZ Kenneth. Teoría de la Política Internacional. Buenos Aires: Grupo Editor Latinoamericano, 1988, p. 174. 